\title{
AS AUDIÊNCIAS DE CUSTÓDIA NA CIDADE DO RIO DE JANEIRO: UM OLHAR SOBRE A PRÁTICA E SEU FUNCIONAMENTO
}

\section{THE CUSTODY HEARINGS IN THE CITY OF RIO DE JANEIRO: A LOOK AT THE PRACTICE AND ITS FUNCTIONING}

\author{
Antonio Eduardo Ramires Santoro ${ }^{1}$ \\ Flavio Mirza Maduro ${ }^{2}$ \\ Anderson Rocha Rodrigues ${ }^{3}$
}

\section{Resumo}

O presente trabalho é parte das conclusões de trabalho de pesquisa desenvolvido pelos autores no âmbito do Programa de Pós-Graduação em Direito na Universidade Católica de Petrópolis. O objetivo é observar e analisar o funcionamento efetivo das audiências de custódia na cidade do Rio de Janeiro. Com o olhar direto como observador participante sobre o acompanhamento da estrutura e atividade prática dos serventuários envolvidos na central das audiências de custódia de janeiro de 2016 a março de 2017, bem como na estrutura formal e conteúdo de 300 atas de audiência, após análise qualitativa, foram identificados os problemas e as dificuldades das audiências de custódia tanto no que se refere ao seu funcionamento, como na elaboração das estatísticas amplamente divulgadas pelo CNJ.

Palavras-chave: Audiência de Custodia; Cidade do Rio de Janeiro; Funcionamento; Prática.

\begin{abstract}
The present work is part of the conclusions of research work developed by the authors in the scope of the Post Graduate Program in Law at the Catholic University of Petrópolis. The objective is to observe and analyze the effective functioning of custody hearings in the city of Rio de Janeiro. With a direct view as participant observer on the follow-up of the structure and practical activity of the servants involved in the central of custody hearings from January 2016 to March 2017, as well as the formal structure and content of 300 minutes of the hearing, after a qualitative analysis, the problems and difficulties of custody hearings were identified both in terms of their functioning and in the preparation of statistics widely disseminated by the CNJ.
\end{abstract}

Keywords: Custody Hearing; City of Rio de Janeiro; Operation; Practice.

\footnotetext{
1 Pós-Doutor pela Universidad Nacional de La Matanza - Argentina. Professor Titular do IBMEC/RJ. Professor Adjunto da Faculdade Nacional de Direito da Universidade Federal do Rio de Janeiro FND/UFRJ. Professor Adjunto do Programa de Pós-Graduação em Direito da Universidade Católica de Petrópolis - PPGD/UCP. Coordenador do Grupo de Pesquisa "O sistema penal sob olhar crítico" UFRJ/UCP. E-mail: antoniosantoro@direito.ufrj.br

2 Pós-Doutor pela Universidade de Coimbra. Professor Adjunto de Direito Processual Penal da UERJ Universidade do Estado do Rio de Janeiro. Professor Adjunto do Programa de Pós-Graduação em Direito da Universidade Católica de Petrópolis - PPGD/UCP. Coordenador do PPGD/UCP. E-mail: flaviomirza@gmail.com

3 Mestrado em Direito pela Universidade Católica de Petrópolis PPGD/UCP. E-mail: rocha.rodri@bol.com.br
} 


\section{INTRODUÇÃO}

Dando cumprimento ao artigo 7, item 5 da Convenção Americana de Direitos Humanos, o CNJ editou a Resolução CNJ no 213/2015 para regulamentar a audiência de custódia. Em 2015, o referido conselho determinou como meta a implementação da audiência de custódia em todos os estados da federação.

O Tribunal de Justiça do Estado do Rio de Janeiro implantou em sua jurisdição a Audiência de Custódia por meio da Resolução no 29/2015, posteriormente alterada pela Ementa no 32, de 11 de setembro de 2015.

O objetivo deste trabalho não é conhecer a referida resolução, mas observar e analisar sua aplicação prática, como a central da audiência de custódia se estruturou, como funciona no seu cotidiano, que mazelas são observáveis da sua implementação prática no Rio de Janeiro.

Os problemas que se pretendem enfrentar aqui são: as previsões normativas sobre a audiência de custódia são cumpridas na consecução prática tal como ela vem se realizando na cidade do Rio de Janeiro? Que problemas e dificuldades são possíveis de observar no acompanhamento pessoal da execução prática do funcionamento das audiências de custódia na cidade do Rio de Janeiro?

Para tanto foi feito uma pesquisa de campo de janeiro de 2016 a março de 2017, em que se acompanhou pessoalmente o dia a dia do funcionamento da serventia, bem como realizou-se a leitura de mais de trezentas atas. Observou-se o funcionamento de coleta de dados estatísticos do estado e do CNJ e sua alimentação pelos serventuários. Observou-se a atitude dos profissionais envolvidos com a audiência de custódia e o conteúdo das suas intervenções.

\section{METODOLOGIA}

\section{A Construção Do Percurso Metodológico}

Na esteira do entendimento da antropóloga Miriam Goldemberg (2004, p. 105), segundo a qual a metodologia "faz um questionamento crítico da construção do objeto científico, problematizando a relação sujeito-objeto construído. Diante de uma objetividade impossível [...] busca uma subjetividade controlada por si mesma (autocrítica) e pelos outros (crítica)", realizou-se a caracterização dos atributos que distinguem o presente estudo, pelo que 
se concluiu que o mesmo pode ser definido como pesquisa empírica, baseada em observação participante, análise documental, banco de dados e dados estatísticos.

Tudo isso realizado de modo a permitir maior e melhor aproximação entre o observador e o todo observado, desta forma favorecendo que sejam descortinados saberes e práticas que permaneceriam ocultos ao olhar distanciado e pretensamente neutro (TRIVIÑOS, 1990).

Antes, porém, de que sejam apresentados, de modo mais específico, os caminhos percorridos, julga-se oportuno tecer breves considerações acerca do que se pretendeu que fosse entendido ao definir-se o estudo ora em tela como uma pesquisa empírica.

O olhar empírico não é, historicamente, a escolha da pesquisa jurídica, mais compromissada com a articulação dogmática, mas disso não decorre, necessariamente, seu maior ou menor valor. Um olhar diferente, uma nova ótica, pode ser ou não relevante, porque o novo não é, obrigatoriamente, melhor, cabendo, justamente por isso, explorá-lo.

Nesse sentido, cabe reconhecer que o presente estudo é em todo embasado por método de pesquisa que busca "o reconhecimento da relevância da realização de pesquisas empíricas, que envolvam trabalho de campo, de caráter etnográfico e comparativo, para a compreensão do Direito e de suas instituições" (KANT DE LIMA \& LUPPETI BAPTISTA,2014, p. 4).

Dito de outra forma, o presente estudo alinha-se à percepção de valor consolidada pelo reconhecimento de que o diálogo entre o Direito e a Antropologia - que, em larga medida, justificou a incorporação da Antropologia Jurídica nos currículos de graduação em Direito - não seja apenas potencialmente fértil, mas visceralmente necessário, em busca de uma menor ênfase dogmática e, nesse sentido, maior compromisso com seu substrato social. Nas palavras de Sebastião Patrício Mendes da Costa:

A Antropologia é marcada pelo estranhamento e pela comparação. O estranhamento como capacidade do antropólogo se surpreender com questões vistas como naturais e comuns aos olhos dos demais pesquisadores, permitindo a relativização das categorias, permitindo inclusive a desconstrução de verdades. Essas características da Antropologia aliadas a sua metodologia podem auxiliar o Direito a compreender melhor situações reais, entendendo melhor a realidade onde os direitos são aplicados, suas instituições, enfim, resolver talvez uma das maiores críticas que o Direito recebe na atualidade que é o afastamento das discussões jurídicas e legais do contexto fático, um distanciamento da sociedade (COSTA, 2015, p. 81).

É interessante destacar que a demanda pela incorporação do olhar empírico pelo Direito não é recente. Ainda na década de 1980, Kant de Lima (1983, p. 92) já apreciava essa questão e apontava o descaso a ela consignado, como se o Direito não fosse uma ciência social 
aplicada, ou ainda, como se os operadores do Direito não fossem eles próprios parte do corpo social.

Tudo isso remete, em última análise, aos modos e mecanismos subjacentes à construção do saber jurídico, a partir do que se torna mais acessível à compreensão dos desafios de conhecer o direito para além do campo dogmático, mas cientificamente conhecê-lo a partir de sua realidade social " (LUPPETI BAPTISTA, 2010, p. 133-134).

Mister é, portanto, reconhecer o desafio implícito à tarefa ora desenhada, considerando-se que:

[...] O fazer antropológico pressupõe a relativização de verdades consagradas, enquanto o fazer jurídico através delas se reproduz, sendo este contraste metodológico um significativo obstáculo ao diálogo destes campos (KANT DE LIMA \& LUPPETI BAPTISTA, 2014, p. 8).

Para a condução desse diálogo, uma possibilidade é que a pesquisa jurídica se aproprie de um dos mais valiosos métodos de investigação antropológica: a observação participante. $\mathrm{Na}$ década de 1950, um livro que, inicialmente, despertou pouco interesse e, mais tarde, daria origem à tese de doutorado de seu autor, passou a ser considerado um dos melhores guias para a compreensão da observação participante (WHYTE, 1955).

Quase quatro décadas mais tarde, o mesmo autor revisitaria o método (Whyte, 1991), sem, no entanto, modificá-lo de modo substancial, mantendo a perspectiva que permitiu a síntese da observação participante em dez mandamentos. No entanto, como afirmado por Gilberto Velho no prefácio de "Sociedade de Esquina" (Whyte, 2005), a tradução dessa obra para o português, apesar do grande lapso temporal, foi decisiva para maior disseminação da perspectiva entre os pesquisadores brasileiros.

1. A observação participante, implica, necessariamente, um processo longo; [...]

2. O pesquisador não sabe de antemão onde está "aterrissando", caindo geralmente de "paraquedas" no território a ser pesquisado; [...]

3. A observação participante supõe a interação pesquisador/pesquisado. As informações que obtém, as respostas que são dadas às suas indagações, dependerão, ao final das contas, do seu comportamento e das relações que desenvolve com o grupo estudado; [...]

4. Por isso mesmo o pesquisador deve mostrar-se diferente do grupo pesquisado. Seu papel de pessoa de fora terá que ser afirmado e reafirmado. Não deve enganar os outros, nem a si próprio; [...]

5. Uma observação participante não se faz sem um "Doc", intermediário que "abre as portas"; $[\ldots]$

6. O pesquisador quase sempre desconhece sua própria imagem junto ao grupo pesquisado; [...]

7. A observação participante implica saber ouvir, escutar, ver, fazer uso de todos os sentidos; [...] 
8. Desenvolver uma rotina de trabalho é fundamental; [...]

9. O pesquisador aprende com os erros que comete durante o trabalho de campo e deve tirar proveito deles, na medida em que os passos em falso fazem parte do aprendizado da pesquisa; [...] e

10.0 pesquisador é, em geral, "cobrado", sendo esperada uma "devolução" dos resultados do seu trabalho (WHYTE, 2005, p. p. 301310).

A observação foi escolhida dentre outras técnicas de coleta de dados no presente trabalho pela possibilidade da percepção de situações que a análise documental e o acesso a banco de dados não seriam capazes, por si só, de prover o necessário aporte informacional.

\subsection{A Exploração Do Campo}

O momento de exploração do campo teve início com a seleção do espaço de pesquisa e a elaboração de estratégia para entrada no campo.

Elegeu-se o TJRJ por concentrar a realização das audiências de custódia dos flagrantes efetuados na cidade do Estado. Tais flagrantes estão sob a competência da Justiça Estadual, uma vez que cada Tribunal Estadual, bem como os Tribunais Regionais Federais possuem uma regulamentação singular, portanto optou-se em pesquisar a realidade do TJRJ, além de, após revisão de literatura, encontrar uma grande maioria de trabalhos que demonstrem apresentações estatísticas e pouca análise qualitativa sobre o tema.

Tal escolha, cabe que seja observado, mais do que tributária da acessibilidade geográfica, refletiu o interesse pelos desdobramentos gerados pela Resolução TJ no 29/2015 do Estado do Rio de Janeiro que, concebida e implementada ao largo da desejável participação do Ministério Público, tem sido alvo de reiteradas e contundentes críticas (LIMA, 2016).

Optou-se em não ampliar a pesquisa para os flagrantes de competência da Justiça Federal, uma vez que o Tribunal Regional Federal da 2을egião (TRF2), com jurisdição no estado do Rio de Janeiro, implantou a realização das audiências de custódia tomando por base a experiência do TJRJ, onde reservou espaço no foro Marilena Franco com a criação da Central de Audiências de Custódia (CAC).

Após a seleção do TJRJ, optou-se pelo micro espaço da Central de Audiência de Custódia, onde se concentra o grande fluxo de flagrantes realizados na cidade do estado. Nesse cenário foi possível apreender como se dá o modelo de organização do trabalho, a definição das atividades, bem como a distribuição do espaço físico.

Para a entrada no campo, o primeiro pesquisador compareceu ao cartório da Central de Custódia localizada no 9o andar do TJRJ, expondo para a chefia sobre a intenção de realizar a 
coleta de dados para a pesquisa e para isso precisava de autorização para assistir as audiências além do pedido de aceitação como voluntário a trabalhar por 1 dia da semana no cartório com a finalidade de entender na prática o funcionamento do trabalho realizado e coletar os dados.

Obtido o aceite no trabalho voluntário realizado no cartório o pesquisador foi informado que para assistir as audiências de custódia o pedido deveria ser feito verbalmente, dia a dia, diretamente ao magistrado que conduziria a audiência, o que foi feito e sempre houve concordância. Excepcionalmente, presença do pesquisador não foi autorizada em uma única ocasião, em que o custodiado era tratado com um esquema diferenciado pela segurança por ser um conhecido líder no comando do tráfico de drogas.

No que concerne às suas instalações, a Central de Custódia conta com 4 salas onde são realizadas as audiências, organizadas com o espaço destinado ao magistrado, seu assessor, e ao membro do Ministério Público na parte superior do tablado e a defesa juntamente com o custodiado na parte inferior, onde permanecem os policiais militares que realizam o transporte do custodiado nas dependências do tribunal.

As salas de audiência dispõem de computadores, microfones e câmeras que capturam a realização da audiência para posterior armazenamento em mídia.

No espaço destinado à Central de custódia há também 2 salas para a realização de audiência por vídeo conferência, ainda não utilizadas, 2 salas destinadas aos custodiados, 1 sala para a perícia, 2 salas para a equipe multidisciplinar e o cartório.

O comparecimento ao TJRJ se deu sempre às segundas-feiras, com a finalidade de assistir às audiências de custódia, que são iniciadas por volta das $13 \mathrm{~h}$. A escolha desse dia da semana deveu-se ao fato do mesmo concentrar maior movimento, uma vez que poucas audiências são realizadas em finais de semana e feriados, sempre a critério do juiz escalado para o plantão judiciário. Essa primeira fase, que teve como objetivo tomar maior ciência do procedimento e da dinâmica dos agentes envolvidos e foi conduzida no período de outubro a dezembro de 2016, tendo sido produzidas notas e apontamentos acerca de 130 audiências de custódia.

Percebeu-se que as informações colhidas em audiência revelavam elevada prevalência de certos conteúdos. Dito de outra forma, após análise do material coletado para sua classificação, observou-se que os dados se mostravam repetidos e que havia semelhança e confirmação dos dados.

Para o registro das observações foi utilizado um diário de campo composto por uma parte descritiva que consistia nos apontamentos do que era observado na realização das 
audiências, isto é, a descrição das perguntas realizadas e suas respectivas respostas além da descrição de comportamentos que se diferenciassem dos demais casos.

Em virtude da agilidade e rapidez com que se dá a audiência, optou-se por breve anotação no momento em que se estava presente na sala de audiência, de maneira a captar melhor todo o contexto, deixando para realizar um relato detalhado do que fora observado logo após a saída do TJRJ, para que não houvesse esquecimento do que fora presenciado.

Concluída essa primeira etapa, um segundo momento teve lugar entre os meses de janeiro de 2016 e março de 2017.

Esse segundo contato, o primeiro pesquisador verificou, atuando como voluntário no cartório da Central de Custódia, em que pese todo o empenho e dedicação dos que ali atuam, uma clara insuficiência de recursos estruturais e humanos, o que poderia ter impacto adverso relevante sobre a operacionalidade do estudo. Esta condição foi de grande peso tanto para a decisão do pesquisador, como para o aceite pela equipe da Central de Custódia para o desenvolvimento de um trabalho voluntário.

Essa etapa teve por objetivo o acesso ao banco de dados do DCP e às atas das Audiências de Custódia, bem como à inserção de dados no Sistema de Audiência de Custódia (SISTAC), de modo que houve a coleta dos seguintes dados: número de juízes, casos de reincidência, casos de relatos de agressão no momento da prisão, tipificação do suposto crime, qual foi a decisão e os motivos dessa decisão dentro do período analisado.

Ao realizar o cadastro no Sistema de Audiência de Custódia notou-se uma grande dificuldade, pois o programa utilizado pelo TJRJ, Distribuição de Controle de Processos (DCP) é utilizado para consultar as informações necessárias de abastecimento do SISTAC. Ocorre que o DCP não contempla toda a base de dados que o SISTAC possui e por isso alguns dados ficam sem ser lançados, além da demora de preenchimento dos dados uma vez que se utilizam dois programas com plataformas diferentes ao mesmo tempo: o DCP e o SISTAC.

A população de estudo, nessa etapa, foi constituída pelas atas de Audiências de Custódia realizadas no período de janeiro de 2016 a março de 2017, selecionadas aleatoriamente 20 atas do mês considerado. O procedimento adotado permitiu a análise das decisões de um número maior de juízes, uma vez que cada turma, composta por 4 juízes cumpre rodízio de 4 meses, passível de renovação, conforme dispõe o artigo 9o da Resolução 29/2015 do TJRJ. 
Os dados quantitativos foram processados por meio do ferramental da Estatística Descritiva e os dados qualitativos, colhidos da leitura das atas das Audiências de Custódia, foram tratados por meio de Análise de Conteúdo, tal como descrita por Laurence Bardin (2011).

A análise de conteúdo, em sentido lato, pode ser definida como um conjunto de instrumentos metodológicos, em constante aperfeiçoamento, que se presta a analisar diferentes fontes de conteúdo, que tanto podem ser verbais ou não verbais.

A condução da análise dos dados, por sua vez, abarca várias etapas, de modo a conferir significado aos dados coletados.

A primeira fase ou pré-análise tem por finalidade a organização e a sistematização do material coligido.

A segunda fase compreende o tratamento dos resultados, inferência e interpretação, consiste em captar os conteúdos manifestos e latentes contidos em todo o material coletado.

Ademais, um esclarecimento: ao longo da apresentação dos resultados, alguns elementos metodológicos emergirão pontualmente. Ao assim proceder, pretendeu-se não apenas a maior clareza discursiva, mas o maior compromisso ético com a verdade dos fatos, das informações e dos contextos.

Em resumo, o percurso metodológico construído conjugou e articulou em um todo cognoscível dados e informações coletados em três fontes: [1] as notas e observações feitas a propósito das Audiências de Custódia presenciadas no TJRJ, em um total de 130 (cento e trinta) registros, cada um referente a uma Audiência de Custódia presenciada no período de outubro a dezembro de 2016; [2] o diário de campo onde foram registradas as observações sobre a Central de Audiência de Custódia, suas rotinas e processos de trabalho, o qual contemplou o período de outubro de 2016 a março de 2017; e [3] as atas das Audiências de Custódia que foram submetidas à Análise de Conteúdo, em um total de 300 (trezentas) atas analisadas, cuja realização ocorreu no período de janeiro de 2016 a março de 2017, observando-se média de 20 (vinte) atas/mês, de modo a assegurar a representatividade da amostra.

Em relação a essa terceira fonte, faz-se oportuno esclarecer que, de posse dos registros, foi criada uma planilha, separando-se no período estudado os seguintes dados: número de juízes, casos de reincidência, casos de relatos de agressão no momento da prisão, tipificação do suposto crime, qual foi a decisão e os motivos da mesma.

Como indicado anteriormente, a coleta nas fontes 2 e 3 ocorreu em períodos parcialmente sobrepostos. Destarte, durante esse período também foi observado como se dá o trabalho da perícia e da equipe multidisciplinar, que serão abordados em tópicos próprios. 
Os dados e informações oriundos da fonte 1, por sua vez, foram incorporados ao relato da logística procedimental e, de modo mais direto, em tópico individualizado, precedendo a exposição dos resultados consolidados a partir da fonte 3 .

Compôs-se, assim, um mosaico informacional, de modo a gerar com maior fidedignidade a descrição dos principais aspectos da implementação da Audiência de Custódia no Rio de Janeiro.

A construção desse todo cognoscível cabe destacar, foi mediada pela interlocução entre as fontes, ora seus achados se complementando, ora sugerindo a presença de dissonâncias.

Assim sendo, os resultados apresentados a seguir são produto dessa explicitação, ou seja, do esforço de desvelamento realizado pelos pesquisadores, à luz dos referenciais revisados e, não com menor importância, de sua própria formação, do seu modo de ver o mundo e interpretá-lo.

\section{APRESENTAÇÃO DOS RESULTADOS}

\section{Da Logística Procedimental}

O número de audiências realizadas varia conforme o dia, há dias em que não são realizadas audiências e outros dias com mais de 100 casos a serem analisados. Tal variabilidade se explica por diversos fatores, dentre eles: segundas feiras e dia útil após feriados são os dias com o maior número de audiências, as greves do pessoal da Secretaria de Estado de Administração Penitenciária (SEAP) e do pessoal da Polícia Civil, são fatores que também influenciam na não realização das audiências, devido às dificuldades operacionais impostas ao transporte dos presos.

Constatou-se que, a despeito da inexistência de tal previsão na Resolução TJRJ no 29/2015, em todos os casos houve presença de representantes do Ministério Público e da Defensoria Pública, este último, exceto nos raríssimos casos em que o custodiado dispunha de advogado por ele constituído por meios próprios.

Ao conduzir a audiência o magistrado cientifica os presentes sobre a utilização do registro fonográfico/audiovisual e que as declarações colhidas serão gravadas e salvas em CD e que será acautelado no cartório da Central de Custódia.

Após isso, o magistrado realiza várias perguntas ao custodiado sobre sua qualificação, residência, renda, escolaridade, estado civil, se já foi preso e alguns juízes buscam saber até se o custodiado possui tatuagens. 
Respondidas tais indagações, abre-se a palavra ao membro do Ministério Público que, via de regra, requer a conversão do flagrante em prisão preventiva e, depois, à defesa, que requer a liberdade provisória, solicitando a substituição da prisão por medidas cautelares. Em raríssimos casos são juntados pela defesa comprovante de residência ou de trabalho regular do custodiado, em virtude do pouco tempo existente entre a prisão e a realização de entrevista com o defensor. Ao final, o juiz passa a decidir.

Cabe salientar algumas particularidades sobre a estruturação para a realização das Audiências de Custódia no do Rio de Janeiro, pois diferentemente do que foi pensado nos passos iniciais da pesquisa notou-se que a única Central de Custódia do Rio de janeiro não atende a todo Estado, pois somente os flagrantes encaminhados pelas delegacias localizadas na cidade que são realizadas as Audiências de Custódia, assim, a Baixada Fluminense, Niterói, Região dos Lagos e o interior do estado do Rio de Janeiro ainda não realizam as referidas audiências.

Há uma iniciativa do presidente do TJRJ, desembargador Milton Fernandes de Souza, para criar no estado mais 3 Centrais de Custódia, que tem por fulcro a diminuição da população carcerária nos presídios cariocas, bem como evitar o transporte de custodiados do interior para a capital, como desdobramento direto, não apenas são reduzidos os custos, uma demanda urgente no contexto de extrema penúria hoje vivenciado, mas também se agrega maior segurança ao procedimento como um todo. Ao que se sabe, a iniciativa pretende implementar até setembro de 2017 outras unidades para a realização das audiências, conforme notícia veiculada no sítio eletrônico do TJRJ. ${ }^{4}$

O número de serventuários é insuficiente para a grande carga de trabalho que a Central de Custódia recebe diariamente: apenas 03 (três) funcionários, que contam com a ajuda de estagiários para realizar as diversas funções do cartório. Embora não caiba colocar em xeque a dedicação dos que ali atuam, claramente compromissados com a imensa carga de trabalho, existem limites de exaustão que, em curto prazo, podem desdobrar-se em queda da produtividade e, não com menor importância, da qualidade dos serviços prestados. Tudo isso não é inócuo, antes repercutindo de modo direto e relevante sobre a vida de todos os envolvidos, notadamente dos custodiados. Ademais, os que ali atuam estão próximos de conquistar o direito à aposentadoria por tempo de serviço e sem que se cuide da alocação de novos serventuários, corre-se o risco da descontinuidade do que já foi possível conquistar.

\footnotetext{
${ }^{4}$ Notícia publicada pela Assessoria de Imprensa em 07/06/2017 10:24. Acesso em 17 de junho de 2017.
} 
Percebeu-se que qualquer estatística em âmbito nacional se mostra desatualizada, pois basta pensar que a Central de Custódia do Rio de Janeiro estava lançando dados das audiências realizadas em novembro de 2016 no mês de fevereiro de 2017.

A logística empregada exige retrabalho. O Sistema utilizado na Central de Custódia, DCP, é abastecido rapidamente por um serventuário. Este, assim que recebe o processo físico das delegacias ou do plantão judicial, insere os dados pessoais do custodiado e circunstâncias da prisão para que o juiz dele se utilize e inclua a decisão. O mesmo Sistema fica disponível tanto para o Juiz, que o utilizará para a realização da audiência quanto para o cartório.

Ocorre que a maioria dos dados lançados no DCP é posteriormente relançado no SISTAC, pois não há comunicação entre os sistemas, o que dificulta em muito a atualização dos dados no SISTAC, sendo mais fidedignos os dados do DCP. Destarte, a persistência desse cenário acarretará a inviabilidade de um controle eficiente, eficaz e efetivo das Audiências de Custódia em âmbito nacional, motivação precípua da existência do SISTAC.

É preocupante que o SISTAC forneça os dados estatísticos nacionais e regionais mesmo desatualizados, sem qualquer menção aos períodos de referência, potencialmente induzindo aos que consultarem tais dados, sejam leigos ou especialistas, a equívocos de maior ou menor repercussão. Por exemplo, ao solicitar a quantidade de audiências realizadas em todo país de novembro de 2016 até fevereiro de 2017, os dados do Rio de Janeiro que estavam em fase de inserção das audiências de novembro de 2016, entram na estatística compondo o somatório até fevereiro de 2017, conforme consulta realizada em fevereiro de 2017. 
Figura 2 - Print da tela do SISTAC com a representação dos dados lançados no período de setembro de 2016 a fevereiro de 2017, nacional.

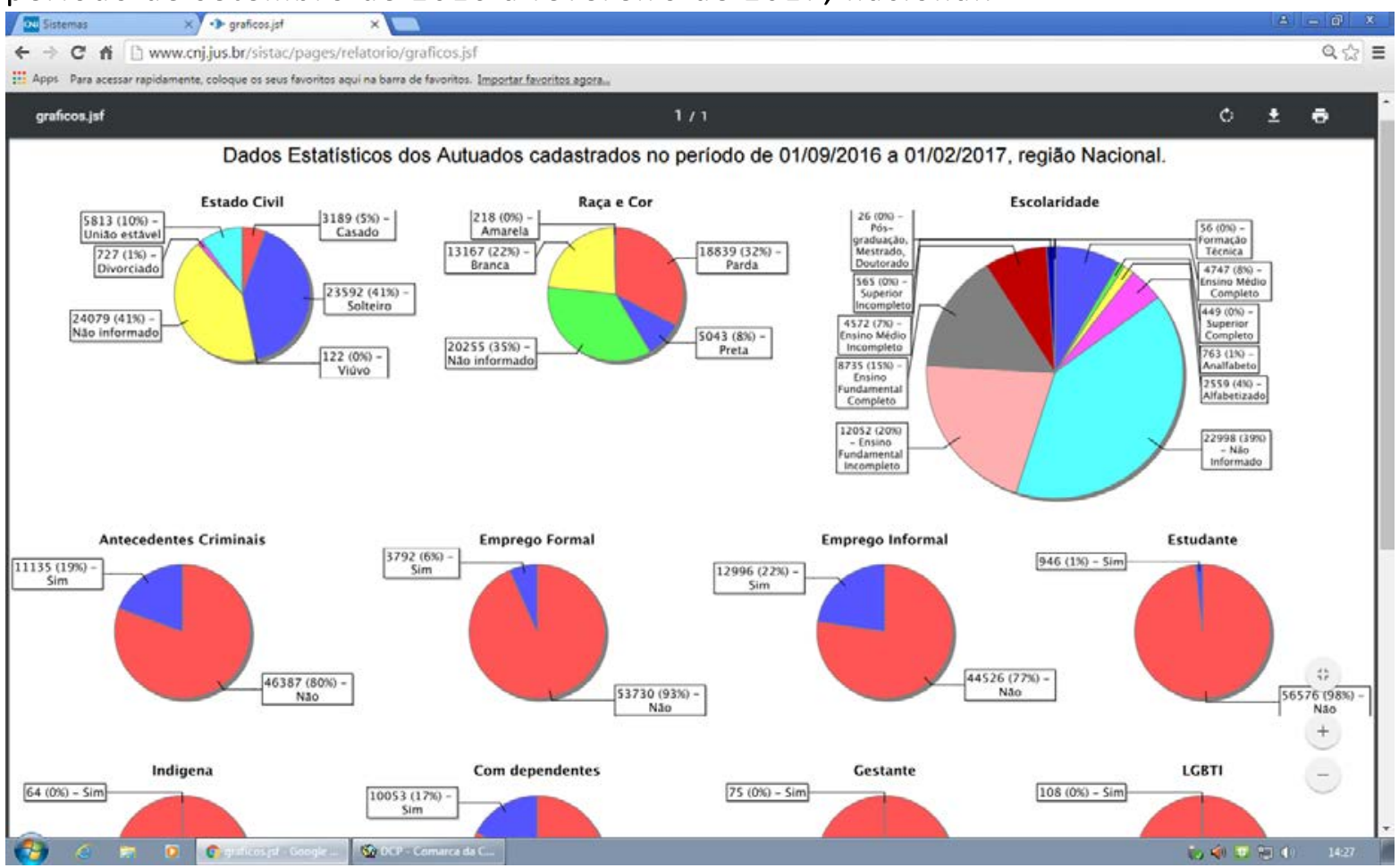

Figura 3 - Print da tela do SISTAC com a representação dos dados lançados no período de setembro de 2016 a fevereiro de 2017, região Rio de Janeiro.

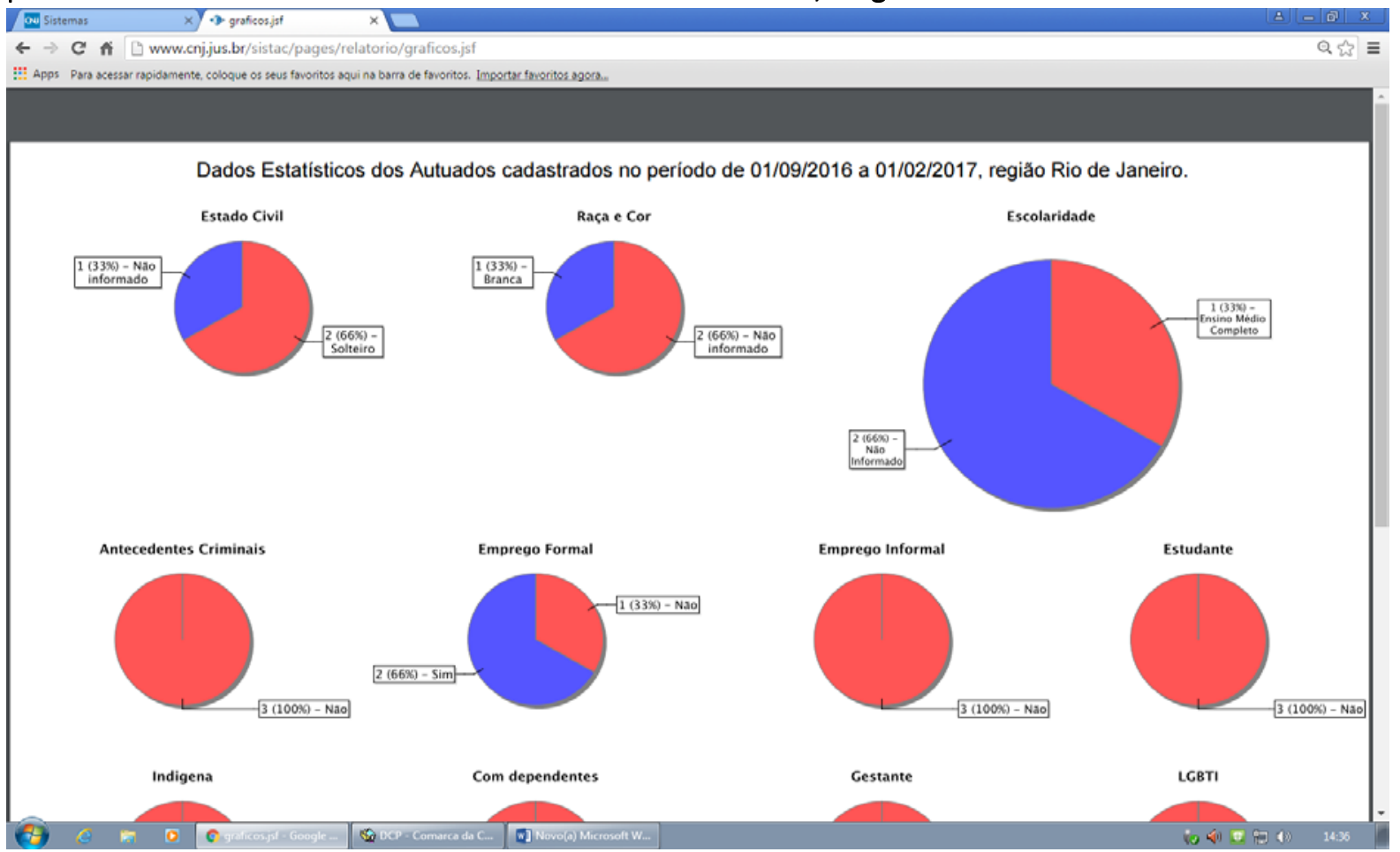


As duas figuras foram captadas no mês de fevereiro de 2017 e embora apresentem estatísticas do período de setembro de 2016 até fevereiro de 2017, âmbito nacional e estadual, as mesmas se mostram desatualizadas, uma vez que em fevereiro de 2017 os dados lançados no SISTAC remontavam o período de novembro de 2016.

Os juízes que realizam as audiências são escalados pela Presidência do Tribunal e ficam por quatro meses nessa função, podendo renovar caso haja interesse. Via de regra, são dois juízes por dia, mas podem ser até mesmo três ou quatro. Em geral, não são realizadas audiências à noite, aos finais de semana e feriados.

O flagrante no cometimento de ato infracional por menores é analisado no Núcleo de Audiência de Apresentação (NAAP) localizado no Plantão Judicial.

Apesar do grande número de estrangeiros flagrados na cidade do Rio de Janeiro, foi verificado que a estrutura da Central de Custódia ainda não está preparada para atender a contento tais casos.

Um caso que chamou a atenção foi o de um custodiado natural da Colômbia que teve a comunicação do flagrante pela suposta prática do crime de furto e que por não falar a língua portuguesa não foi possível realizar a Audiência de Custódia dentro do prazo de 24 horas. 0 custodiado retornou para a carceragem e, no dia seguinte, foi encaminhado novamente à Central de Custódia, que entrou em contato com o Serviço de Rogatórias, Extradições e Interpretações (SEREI), localizado do TJRJ, para solicitar a presença de um intérprete. No entanto, a solicitação exige agendamento, e por isso, impôs-se novo adiamento para 06 dias após a primeira apresentação do custodiado para a realização da Audiência de Custódia.

\section{Da Perícia}

Os custodiados que chegam para a Audiência aguardam na carceragem do Tribunal, quando são entrevistados pela defensoria pública e, em raríssimos casos, por advogado constituído. Nessa ocasião, também passam por um perito da Polícia Civil, cedido à Central de Custódia, que realiza a entrevista pessoal com o preso, perguntando-Ihe se sofreu agressão no momento da prisão e, em caso afirmativo, solicita sua autorização para examiná-lo. Todavia, mesmo nos casos em que o custodiado afirma não ter sofrido agressão no momento da prisão, mas encontra-se visivelmente machucado, o perito pergunta-lhe sobre a origem da lesão, fazendo constar no laudo o relatado pelo custodiado. O laudo é anexado ao processo e o juiz ao realizar a audiência busca saber também a origem das lesões, encaminhando-o para uma perícia posterior no IML. 
O problema é que o custodiado posto em liberdade recebe o encaminhamento e, na maioria das vezes, não vai realizar o exame de corpo de delito solicitado pelo juiz junto ao IML. Isso, cabe sublinhar, impossibilita a averiguação sobre maus tratos ou tortura ocorridos.

Situação diversa é observada no tocante aos que não foram postos em liberdade, uma vez que os custodiados que tem o flagrante convertido em prisão preventiva são levados, após o término da Audiência de Custódia, ao IML.

Todas as informações no que diz respeito às lesões e aos relatos de agressão são juntados ao processo que será analisado pelo juízo competente por distribuição.

Constatou-se ainda a insuficiência de peritos, sendo especialmente digno de nota que o quadro nunca esteve completo desde o início da criação da Central de Custódia. Considerandose que seria necessário ao menos um perito por dia de atividade, a demanda mínima seria de cinco peritos. Durante o período da observação participante na Central de Audiência de Custódia, constatou-se que esse número nunca foi maior do que dois peritos.

\section{Da Equipe Multidisciplinar}

A equipe multidisciplinar conta somente com a presença de uma psicóloga e uma assistente social, ambas concursadas. Em virtude da grande carga de trabalho não é possível que todos os presos passem pelo atendimento multidisciplinar, sendo possível atender tão somente aqueles que são liberados para responder o processo em liberdade. Ainda assim, por apenas uma das profissionais que acabam por dividir o serviço para dar conta de atender todos os liberados do cárcere naquele primeiro momento. Como consequência direta, prioriza-se o atendimento psicológico em virtude da percepção de algum sinal de transtorno.

$\mathrm{O}$ atendimento prestado consiste em ouvir o indivíduo e entrevistá-lo, a fim de lançar reflexões e descobrir suas necessidades para tentar de alguma forma ajudar todos aqueles que foram liberados da prisão ao término da Audiência de Custódia. Nessas entrevistas busca-se orientar e motivar a adesão aos serviços e tratamentos disponibilizados na rede de serviços públicos de atenção a saúde, educação, assistência social e de acesso à cidadania. Em muitos casos, apontando claramente para a insuficiência do estado em prover a necessária atenção e o devido acolhimento aos socialmente mais vulneráveis, é o primeiro contato que aquele cidadão tem com um agente do Estado que está disposto a ouvi-lo e ajudá-lo.

O psicólogo dispõe de curto período de tempo para perceber problemas como transtornos mentais e comportamentais relacionados ao uso, abuso ou dependência de drogas lícitas ou não, o que progride com o encaminhamento para um Centro de Atenção Psicossocial 
a Álcool e Drogas (CAPS/AD). Atualmente, entretanto, na cidade do Rio de Janeiro, existem apenas seis desses centros e somente dois são voltados à população adulta, os demais reservados à população pediátrica, que se estende até os 17 anos.

A assistência social realiza seu atendimento por meio de uma entrevista abrangente e compreensiva que busca desvelar a realidade socioeconômica e cultural, do indivíduo.

Embora essa entrevista tenha caráter multidimensional, com o intuito de abarcar aspectos da vida familiar, do acesso a fontes de trabalho e renda, cultura e lazer, dentre outras, constatou-se que a principal demanda é por empregos e por isso a maioria dos atendidos é encaminhada para cadastro em vagas de emprego, bem como para acesso à emissão de documentação básica e em alguns casos a inserção em unidade de acolhimento ou acompanhamento junto à equipe interdisciplinar nos Centros de Referência de Assistência Social do Estado (CRAS e CREAS).

Tendo em vista não haver comunicação dos Órgãos envolvidos nos encaminhamentos realizados pela equipe multidisciplinar, não é possível saber se o assistido aceitou as orientações e buscou ajuda.

Evidencia-se, assim, a grande importância da atuação desses profissionais que em número reduzido levam a cabo trabalho de denotado mérito. No entanto, ampliar o alcance dessa janela de oportunidade de promoção do resgate do indivíduo antes que o mesmo se insira definitivamente na seara penal é objetivo que não impõe apenas o aumento do quantitativo de profissionais alocados nesse momento específico, mas também da disponibilidade de uma rede de apoio e acolhimento que ofereça opções de efetiva inserção social.

Fato que chama atenção é a presença corriqueira de custodiados sem camisa e descalços no momento da audiência, sempre de bermudas, algemados e sujos. Tais cidadãos ao receberem o benefício de responder o processo em liberdade são encaminhados para a equipe multidisciplinar e lá recebem um lanche, uma vestimenta e um calçado que são doados pelos próprios juízes que se revezam na realização das audiências. Contudo, a atitude nobre por parte dos magistrados não é capaz de atender a todos os que necessitam, uma vez que o Estado ainda não criou um mecanismo que melhor atenda essa parcela de necessitados.

Após a intervenção da equipe multidisciplinar, os atendidos recebem um cartão de transporte. O benefício é concedido mediante convênio com a FETRANSPOR, de modo que os beneficiados tenham meios para retornar a seus domicílios, embora não haja meios para acompanhar se isso de fato ocorreu, especialmente no caso dos dependentes químicos. 
Via de regra, os relatos dos liberados possui uma carga forte de emoção e segundo dados fornecidos pela equipe multidisciplinar, a taxa de reincidência nos atendimentos é muito baixa, cerca de 1\% dos casos analisados no período de janeiro de 2016.

Esse dado é compatível com aquele veiculado pelo CNJ em seu portal institucional, em que aponta que a reincidência durante o primeiro ano da implementação da Audiência de Custódia (setembro de 2015 a setembro de 2016) foi de 1,4\%.

No entanto, ambos devem ser considerados com cautela quanto ao fenômeno realmente observado, visto que dificilmente um preso em flagrante que seja liberado para responder o processo em liberdade, mas que volte a ser flagrado, receberá uma nova chance.

O perfil socioeconômico estabelecido a partir de análise conduzida pelos profissionais da equipe multidisciplinar dos atendimentos de janeiro de 2016 demonstrou que a grande maioria é de homens (92\%), com faixa etária entre 18 e 25 anos (52\%), que se declaram como negros e pardos (59\%), possuem ensino fundamental incompleto (52\%) e renda entre um e dois salários mínimos (63\%) e os que vivem em situação de rua totalizam $11 \%$.

O emprego se apresenta quase sempre como subemprego, vendedores ambulantes, guardadores de carro, moto taxistas dentre outros, sem amparo trabalhista e previdenciário algum.

\section{Das Audiências de Custódia Presenciadas}

Foram presenciadas 130 (cento e trinta) Audiências de Custódia e produzidos registros ao término de cada uma das mesmas, de modo a melhor apreender a dinâmica dessas audiências.

No cômputo geral, caracterizam-se por sua relativa brevidade, com média de duração em 15 (quinze) minutos, mas esse tempo pode ser acentuadamente reduzido em dias de maior movimento, situando-se em torno de 10 (dez) minutos.

Em todas as audiências, embora não haja previsão de obrigatoriedade por força da Resolução TJRJ no 29/2015, o MP esteve presente.

Os custodiados dependem expressivamente da Defensoria Pública e, nesta série em particular, apenas 3\% constituíram advogado por meios próprios.

As solicitações por parte tanto do MP como da defesa reproduzem-se praticamente sem alterações. O contato do custodiado com o seu defensor, antes da realização da audiência propriamente dita, é breve e, via de regra, não estão disponíveis documentos que comprovem a fala do custodiado como, por exemplo, comprovantes de residência e/ou de vínculo trabalhista. 
A título de ilustração, são comentados dois casos em que a disponibilidade de tais comprovantes foi essencial para a decisão de que o custodiado respondesse o processo em liberdade.

No primeiro deles, um grupo de quatro jovens foi preso em flagrante em frente a uma padaria localizada em uma comunidade. Com três deles foram encontrados rádios e celulares, sugerindo atividade de vigilância, normalmente relacionada ao tráfico de drogas. Embora nenhum deles portasse comprovante de atividade laboral, o quarto jovem alegou trabalhar na referida padaria e que somente se encontrava no local da prisão por estar em horário de descanso. Os demais jovens também referiram que o mesmo não pertencia ao grupo deles, mas a carteira de trabalho levada pela família foi o maior elemento para o estabelecimento da convicção inicial da veracidade de sua história.

No segundo caso, um homem adulto, bem vestido, foi flagrado dirigindo um carro roubado. No momento do flagrante, assim como durante a Audiência de Custódia, ele alegou haver comprado o carro e que dirigia para a Uber, embora a documentação ainda estivesse irregular, sem a transferência do veículo para o seu nome. A família levou os comprovantes de compra e venda do veículo e, mais uma vez, isso foi decisivo para que a prisão em flagrante não fosse convertida em prisão preventiva.

Por outro lado, a despeito da disponibilidade de qualquer comprovação, o flagrante envolvendo crime com ameaça de morte ou da integridade física da vítima, fosse a posse de arma confirmada ou apenas alegada com o intuito de intimidação, via de regra é convertido em prisão preventiva.

O mesmo também se observa em relação ao tráfico de drogas. Em outro caso, houve recebimento de denúncia dessa atividade em uma casa situada em comunidade. Assim que chegaram ao local, os policiais encontraram cerca de $2 \mathrm{~kg}$ de maconha, o proprietário da casa e algumas outras pessoas que consumiam drogas. Esse proprietário, que já havia cumprido pena por roubo, teve a prisão em flagrante convertida em preventiva, mas não os usuários, que receberam o benefício de responder ao processo em liberdade.

A apresentação física dos custodiados, na maioria dos casos, remete à própria situação de vida dos mesmos. Não raro sujos e maltrapilhos são conduzidos algemados e assim permanecem no recinto da audiência, fato observado em $73 \%$ dos casos. Embora o risco de fuga de um indivíduo não possa ser abstraído de seu porte físico, mesmo custodiados franzinos e de postura passiva não tiveram, em todos os casos presenciados, suas algemas retiradas. 
A disposição física do mobiliário reproduz a dos tribunais clássicos, gerando uma atmosfera francamente inquisitorial, o juiz e o representante do MP estando posicionados com destaque, em um tablado que os coloca acima da linha em que estão posicionados os demais presentes. Essa disposição física, de modo intencional ou não, reproduz relações de poder historicamente consagradas, que não favorecem interlocução igualitária entre os diferentes agentes que ali atuam, tampouco em relação ao custodiado.

Ainda assim, observa-se interesse em que o custodiado tome conhecimento por mínimo que seja das finalidades da audiência e de seus direitos, notadamente a denúncia de agressões e maus tratos. Em muitos casos, a enunciação das finalidades tem por objetivo maior conter as expectativas do custodiado, de modo que ele compreenda que nada ali será decidido além da conversão ou não da prisão em flagrante em prisão preventiva.

Todos os custodiados são esclarecidos acerca do fato de que a audiência é gravada por meios eletrônicos, mas, em geral, não manifestam maior interesse pelo procedimento e/ou suas finalidades.

Alguns juízes ampliam o escopo das indagações, procurando estabelecer se 0 custodiado possui ou não tatuagens, ou ainda, se é dependente de álcool ou drogas. Não fica claro para aqueles que presenciam a audiência, tampouco para o custodiado, o uso que será feito dessas informações, não podendo ser descartado, no entanto, que isso progrida no sentido de convicções preconceituosas acerca do caráter do custodiado.

Na série em tela, $78 \%$ das prisões em flagrante foram convertidas em prisão preventiva, sendo esse percentual alavancado pela maior prevalência de casos envolvendo o tráfico de drogas. Cerca de $43 \%$ dos custodiados eram reincidentes, ainda que não necessariamente pelo cometimento do mesmo tipo penal.

Em sua maioria eram homens jovens, em idade produtiva, mas não inseridos no mercado formal de trabalho. Entre aqueles que possuíam ocupação e renda, o vínculo informal foi majoritário e, em muitos casos, a própria atividade laboral poderia ser tomada como favorecedora do aliciamento por grupos criminosos, como é o caso dos vendedores ambulantes, em especial aqueles que comercializam mercadorias produto de falsificação, ou ainda, moto taxistas, que despertam interesse pela possibilidade de deslocamento ágil, mesmo em terrenos menos acessíveis. 


\section{Das Atas de Audiência}

Os flagrantes verificados no universo das 300 (trezentas) atas analisadas estão relacionados ao cometimento dos seguintes crimes: roubo (art.157 CP), furto (art. 155 CP), estelionato (art.171 CP), Lei de drogas (Lei 11.343/2006), relacionados ao Código de trânsito brasileiro, homicídio (art. 121 CP), Estatuto do desarmamento (Lei 10.826/2003) e corrupção ativa (art. $333 \mathrm{CP}$ ), este sempre atrelado ao cometimento de outro crime.

Dentre os delitos listados acima foram destacados os de maior incidência.

O cometimento dos crimes de roubo é responsável por 30\% dos delitos, já os de furto por $18 \%$, os relacionados com a Lei de Drogas por $28 \%$ e com o Estatuto do desarmamento por $15 \%$.

Ainda sobre o cometimento dos crimes de roubo, percebeu-se entre os comentários informais entre os juízes, promotores e servidores da Central de Custódia sobre o aumento deste tipo de crime relacionado ao roubo de carga, que só seria menor que o roubo de aparelhos de celular.

Percebeu-se que $9 \%$ dos casos analisados envolvem crimes relacionados a estelionato, dirigir sob a influência de álcool, homicídio e corrupção ativa. Em virtude da natureza do delito é que se nota a pouca incidência dos referidos tipos penais nas atas das Audiências de Custódia verificadas, conforme demonstrado no gráfico abaixo.

\section{Gráfico 1- Distribuição dos flagrantes por tipo penal.}

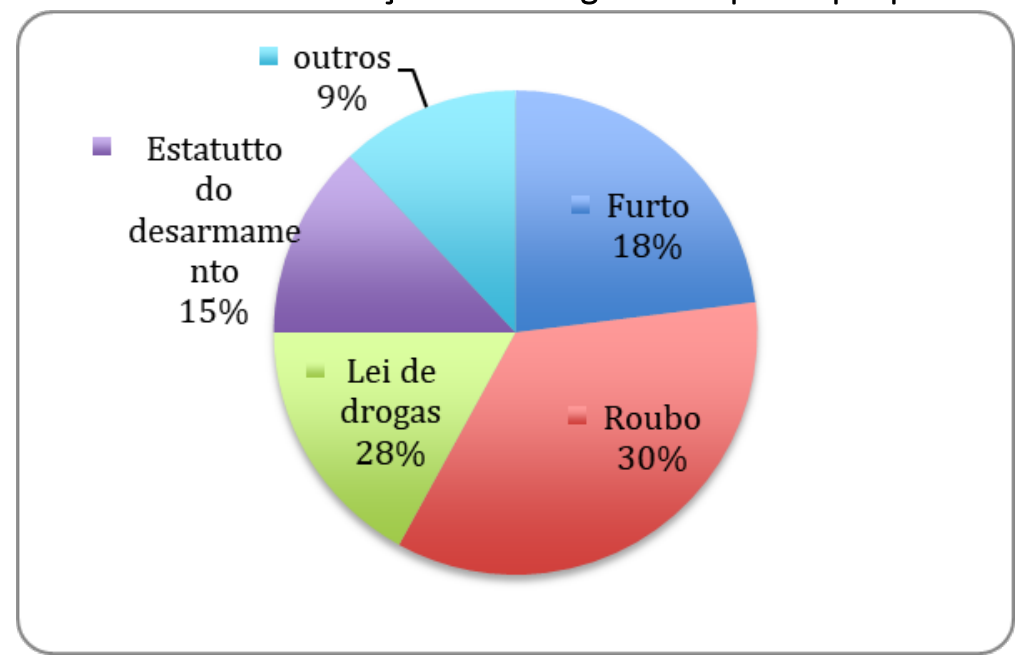

Outros dados que vieram à luz após a análise do material disseram respeito à reincidência, pois se verificou que 37\% eram reincidentes e 53\% não reincidentes e em 10\% dos casos nada foi informado. 
Destaca-se neste ponto que a palavra reincidência é utilizada na maioria das vezes pelos magistrados pela criação de um conceito ad hoc de "reincidência na audiência de custódia", pois o utilizam para aqueles custodiados que são presos em flagrante mais de uma vez e passam novamente pela Central de Custódia e, mesmo quando no termo técnico são primários, por falta de condenação transitada e julgada contra ele.

O resultado que mais chama a atenção é o que diz respeito à agressão no momento da prisão, pois somente em $11 \%$ das atas analisadas o custodiado afirma ter sofrido algum tipo de agressão no momento da prisão, em $87 \%$ dos casos não houve agressão e em $2 \%$ nada foi informado.

\section{Quadro 2 - Total de casos de reincidência e relatos de maus tratos.}

\begin{tabular}{|c|c|c|}
\hline Reincidência & Reincidência & Sofreu agressão no momento da prisão \\
\hline Sim & $40 \%$ & $11 \%$ \\
\hline Não & $53 \%$ & $87 \%$ \\
\hline Não Informado & $7 \%$ & $2 \%$ \\
\hline
\end{tabular}

Fonte: Elaboração própria a partir dos dados colhidos das atas de audiência.

A decisão do juiz no que diz respeito à concessão da liberdade provisória ou pela conversão da prisão em flagrante em prisão preventiva foi de $41 \%$ e 59\%, respectivamente.

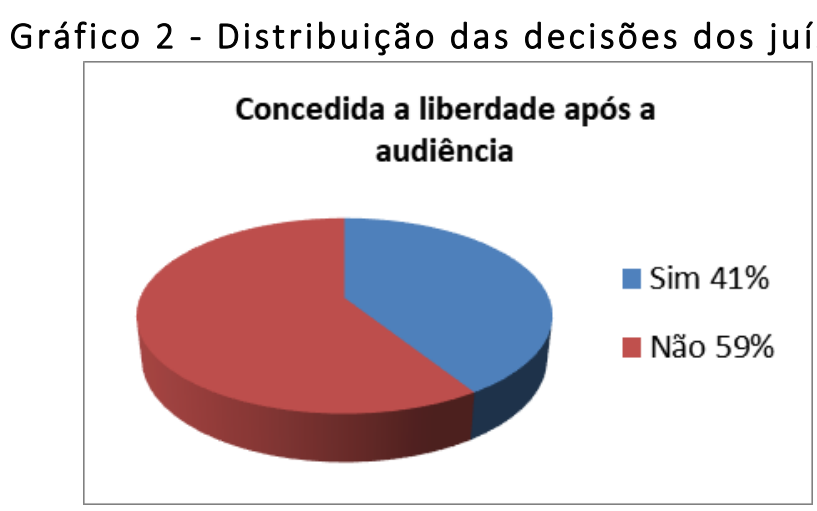

Os Casos de relaxamento da prisão em flagrante pelo motivo de ilegalidade da prisão foram raros, pois somente dois casos foram identificados no universo analisado.

Ademais, procedeu-se ao escrutínio da produção textual consignada nas Atas das Audiências de Custódia coletadas, para tanto empregando a Análise de Conteúdo (BARDIN, 2011).

A esse respeito, faz-se oportuno destacar que diferentes técnicas de organização e análise de dados estão ao alcance do pesquisador empenhado na consecução de pesquisa qualitativa, sendo a Análise de Conteúdo uma escolha possível. Dito de outra forma, a Análise 
de Conteúdo não é per se uma técnica mais eficiente, eficaz ou efetiva, ou mesmo mais acessível. Não obstante, é escolha reiterada no bojo do amálgama que caracteriza o campo das ciências sociais aplicadas.

Tal acolhimento disseminado não está isento de riscos, o mais significativo destes referindo-se ao abandono do procedimento sistematizado em prol de uma abordagem mais intuitiva, para o que alertam diversos autores, dentre eles Alba Judith Alves-Mazzotti e Fernando Gewandsznajder (Alves-Mazzotti \& Gewandsznajder, 2000) e Maria Cecília de Souza Minayo (MINAYO, 2011).

Não cabe, todavia, atribuir este equívoco à mera falta de adestramento no manejo da técnica, embora não seja possível de todo descartá-la. Nesse sentido, ensina Antônio Carlos Gil:

A análise de conteúdo atualmente pode ser definida como um conjunto de instrumentos metodológicos, em constante aperfeiçoamento, que se presta a analisar diferentes fontes de conteúdos (verbais ou não-verbais). Quanto à interpretação, a análise de conteúdo transita entre dois polos: o rigor da objetividade e a fecundidade da subjetividade. É uma técnica refinada, que exige do pesquisador, disciplina, dedicação, paciência e tempo. Faz-se necessário também, certo grau de intuição, imaginação e criatividade, sobretudo na definição das categorias de análise. Jamais esquecendo, do rigor e da ética, que são fatores essenciais (GIL, 2008, p. 47).

Tendo isso em mente, cumpre progredir no sentido da apresentação dos resultados da análise procedida.

Conforme previsão existente no artigo 7o da Resolução TJ-RJ nำ29/2015 (Brasil, 2015), da Ata da Audiência de Custódia deverão constar apenas "o resumo da manifestação do MP, da Defesa e o inteiro teor da decisão proferida pelo Juiz", os procedimentos analíticos iniciais revelaram algumas dissonâncias, explicitadas nos parágrafos subsequentes.

A produção textual conformada pelas trezentas atas analisadas possuem extensão média de 895 palavras, mas observa-se franco emprego dos chamados argumentos de autoridade que, embora em sentido estrito estejam corretos e sejam coerentes, não agregam valor real à apreciação do objeto em análise.

Este fenômeno granjeou recente e maior visibilidade sob a expressão "vestidinho preto", em referência a uma escolha sempre correta, mas que não demanda maior reflexão (EILBAUM, 2012).

Em todas as atas observou-se a existência de um arrazoado que, embora varie entre os juízes, é mantido sem alterações expressivas nas decisões de um mesmo juiz, a despeito do teor do tipo penal apreciado. 
Embora essa conduta não possa ser tida em si mesma como deletéria, constitui provável indicador de que o formalismo analítico esteja preponderando sobre a análise dos fatos em suas especificidades e vicissitudes.

Além disso, considerando-se o contexto específico da Audiência de Custódia no Rio de Janeiro, em que essas Atas são lacradas e arquivadas, não integrando, por conseguinte, autos processuais futuros, o valor dessa conduta torna-se ainda mais intrigante.

Em um caso mais extremo, um texto de 944 palavras, transcrito a seguir, não apenas excede à média das atas, mas o conteúdo não guarda relação de sentido e significado com a natureza do flagrante apreciado:

A presente audiência de custódia tem como escopo resguardar ao cidadão preso em flagrante delito, os preceitos constitucionais fundamentais e individuais elencados nos Tratados e Convenções internacionais, dos quais o Brasil seja signatário, e na própria Constituição Federal, dentre eles, o princípio da dignidade da pessoa humana, da liberdade, além do princípio da não culpabilidade. De toda sorte, não há preceito constitucional de caráter absoluto, e que se sobreponha a outro de igual hierarquia normativa. Os preceitos constitucionais garantidores do direito do preso deverão ser cotejados, à luz do caso concreto, com o princípio fundamental social da segurança pública, além da necessidade de se resguardar a efetividade da prestação da atividade jurisdicional, com o processo justo, célere e de forma efetiva a garantir a segurança jurídica.

E prossegue o Magistrado, detalhando a conduta a ser observada:

A prevalência de um preceito constitucional sobre os demais será aferida, no caso concreto, com os princípios da proporcionalidade e da razoabilidade. A exigência da motivação da decisão deve ser maior com a proporcionalidade, em virtude do imperativo de exame da adequação, necessidade e proporcionalidade em sentido estrito, buscando a relação entre o meio utilizado e o fim a ser atingido. A razoabilidade deve ser entendida sob as perspectivas da equidade, congruência e equivalência na busca da relação entre a medida e o caso concreto ou entre a medida e o critério utilizado, sendo vedado o excesso e o "irrazoável". Em outras palavras, o princípio da razoabilidade, consiste em uma análise do caso concreto na busca por evitar excessos cometidos pela lei ou pelo administrador público. Ao passo que, o princípio da proporcionalidade, consiste em uma regra de interpretação e aplicação dos direitos fundamentais, empregada especialmente nos casos em que um ato estatal, destinado a promover a realização de um direito fundamental ou de um interesse coletivo, implica a restrição de outros direitos fundamentais. O objetivo da aplicação dessa regra é fazer com que nenhuma restrição a direitos fundamentais tome dimensões desproporcionais. Para alcançar esse objetivo, o ato estatal deve passar pelos exames de adequação, da necessidade e da proporcionalidade em sentido estrito. Ou seja, a finalidade da audiência de custódia, como sustentam alguns críticos à ideia, não é o esvaziamento do sistema 
penitenciário como medida de economia orçamentária de forma a gerar insegurança no meio social, mas, garantir e assegurar aos presos em flagrante a concretização de seus direitos individuais fundamentais da dignidade da pessoa humana e da liberdade. A custódia cautelar de restrição da liberdade, por ser medida de exceção, deve ser destinada somente aos presos provisórios que, ao final do processo, com a prestação da atividade jurisdicional definitiva, venham a sofrer a sanção com pena de privação da liberdade, sob pena de não se observar o princípio da proporcionalidade e razoabilidade, por falta de congruência e adequação entre a medida cautelar de restrição da liberdade e a eventual pena a ser aplicada.

E, por fim, coroando exposição claramente pedagógica, como se de fato houvesse um público a ser esclarecido e/ou como se pudesse a mesma surtir efeito positivo sobre as partes e até mesmo sobre o procedimento conduzido, acrescenta:

O alicerce normativo para a realização da audiência de custódia tem como suporte o art. 9o, item 3 do Pacto Internacional dos Direitos Civis e Políticos, cuja norma internacional foi introduzida no ordenamento jurídico interno pelo Decreto Presidencial n. 592/92. Dispõe o item 3o do Decreto Presidencial n. 592/92: "Qualquer pessoa presa ou encarcerada em virtude de infração penal deverá ser conduzida, sem demora, à presença do juiz ou de outra autoridade habilitada por lei a exercer funções judiciais e terá o direito de ser julgada em prazo razoável ou de ser posta em liberdade. A prisão preventiva de pessoas que aguardam julgamento não deverá constituir a regra geral, mas a soltura poderá estar condicionada a garantias que assegurem o comparecimento da pessoa em questão à audiência, a todos os atos do processo e, se necessário for, para a execução da sentença". A Convenção Americana dos Direitos humanos em seu art. 70, item 5, disciplina: "Toda pessoa detida ou retida deve ser conduzida, sem demora, à presença de um juiz ou outra autoridade autorizada pela lei a exercer funções judiciais e tem direito a ser julgada dentro de um prazo razoável ou a ser posta em liberdade, sem prejuízo de que prossiga o processo. Sua liberdade pode ser condicionada a garantias que assegurem o seu comparecimento em juízo". O E. Tribunal de Justiça do Rio de Janeiro editou a regulamentação da audiência de custódia através da Resolução TJ/OE/RJ n. 29/2015, cujo ato normativo regula o procedimento da audiência de custódia no âmbito do Estado do Rio de Janeiro. O juiz no curso da audiência de custódia analisará essencialmente a prisão flagrancial, sob o aspecto da legalidade, da necessidade e da adequação da continuidade da prisão, ou da eventual concessão de liberdade em favor do custodiado, com ou sem a imposição de outras medidas cautelares. O juiz deverá também avaliar o estado de saúde do preso, sob o prisma de eventuais ocorrências de tortura ou de maus-tratos, entre outras irregularidades. Assim sendo, não há mais como sustentar a inconstitucionalidade ou ilegalidade da realização da audiência de custódia, até mesmo, porque o tema já foi objeto de enfrentamento no STF com o RE 4666.343, cuja decisão da Corte Suprema foi no sentido da constitucionalidade da apresentação do preso em 24 horas a autoridade judicial após a sua prisão em situação flagrancial. 
Anuncia-se, então, a passagem ao caso concreto, mas ao contrário do que se poderia esperar, após a garantia de que os direitos do custodiado foram adequadamente salvaguardados, a análise do caso propriamente dito foi laconicamente reduzida a:

A gravidade do crime, a descrição fática do delito imputado ao indiciado, e a sua primariedade, além de possuir domicílio fixo, revelam que a fixação de medida cautelar diversa da prisão é mais adequada e suficiente para o caso concreto do que a medida de restrição da liberdade.

De acordo com as normativas, as manifestações do MP e da Defesa devem ser registradas de forma resumida. A análise dos parágrafos dedicados a esses registros revelou maior uniformidade em relação ao MP, em geral restrita ao requerimento da conversão da prisão em flagrante em preventiva, conforme mídia. Os registros das manifestações da Defesa são menos padronizados, sem, contudo apresentar elementos factuais em favor da adoção de medida cautelar diversa. $\mathrm{O}$ texto a seguir ilustra este achado:

O Ministério Público se manifesta no sentido de ser convertida a prisão em flagrante em prisão preventiva. Em relação efetivamente ao flagrante a Defesa entende não estarem presentes os requisitos da cautelar, razão pela qual requer não seja convertido o flagrante em prisão preventiva.

A manutenção das algemas durante a Audiência de Custódia foi objeto de registro em 100\% das atas analisadas, mesmo sendo vedada expressamente pela Resolução CNJ 213/2015, nos arts. 4 ㅇ e 60 . Em todas estas, foi observado a mesma justificativa para que o custodiado permanecesse algemado, como se segue:

Justificada a manutenção das algemas no custodiado em virtude da situação recente de flagrância, dimensões da sala de audiências, bem como pela necessidade de preservação da integridade física dos presentes.

Registre-se, no entanto, o entendimento consolidado do STF que trata o uso das algemas como uma excepcionalidade, conforme a Súmula 11.

Tal justificativa para manutenção de algemas, não raro, foi identificada em ata em que a decisão judicial progrediu no sentido da "não-periculosidade" do custodiado. Os elementos de análise disponíveis, no entanto, não permitem que seja estabelecido se houve equívoco quanto à real manutenção das algemas, ou ainda se, contrariando ao expressamente prescrito na Resolução TJRJ no 29/2015, a manutenção das algemas é conduta-padrão. A passagem transcrita em seguida ilustra essa possível contradição.

No caso dos autos a infração imputada ao acautelado é desprovida de violência ou grave ameaça e, considerando a natureza da suposta infração, não demonstra periculosidade a atrapalhar o convívio social se permanecer solto. 
Concluídos os procedimentos analíticos iniciais, baseados na leitura crítica do corpo de análise, coube prosseguir na categorização dos elementos textuais, de modo a consolidar uma cadeia de sentidos e significados.

Como ensina Bardin (2011), a análise de conteúdo deve ser conduzida de modo a responder indagações, que devem estar adequadamente explicitadas.

No presente estudo, buscou-se apreender e compreender os elementos de convicção que norteiam as decisões judiciais nas Audiências de Custódia. Ao assim proceder, foi possível identificar que as categorias emergentes possuem estreita identidade com os parâmetros propostos em Resoluções como a Resolução CNJ no 213/2015 e, mais especificamente, a Resolução TJ-RJ no 29/2015.

Entretanto, os conteúdos textuais não foram suficientes para adequada investigação dessa vertente.

Apesar do procedimento de categorização para além da mera repetição dos aspectos a serem contemplados em conformidade com o ordenamento normativo, foi possível corroborar conteúdos apreendidos durante a primeira fase da pesquisa de campo, em que foram presenciadas 130 (cento e trinta) Audiências de Custódia e ao que foi dedicado o tópico precedente.

Aspecto especialmente digno de nota se refere à preponderância do rito formal sobre a análise do caso propriamente dito. Esse potencial deletério, por sua vez, amplia-se quando é considerado que tais audiências possuem extensão média de 15 (quinze) minutos e, conforme destacado na narrativa acerca da logística procedimental, apenas raramente ocorre a juntada de comprovantes de residência e/ou renda.

Ademais, a fala do custodiado é francamente desvalorizada nos casos de reincidência, como se essa, a despeito de outros possíveis elementos de contextualização, fosse por si só suficiente para a conversão do flagrante em prisão preventiva. A passagem a seguir ilustra essa racionalidade, sendo oportuno sublinhar que o enquadramento por tráfico abarca rol expressivo de situações, o que certamente faria oportuno um posicionamento menos generalista.

No que diz respeito à conversão da prisão em flagrante em preventiva, entende esta magistrada que a mesma se apresenta necessária e proporcional, data vênia do entendimento defensivo, devendo ser destacado que o custodiado foi preso por crime grave e é reincidente, fazendo com que seja necessária sua custódia, a fim de garantir a ordem publica e a aplicação da lei penal, já que não há comprovante de 
residência fixa ou emprego lícito, sendo certo que qualquer outra análise nesta fase seria precipitada, já que referente ao mérito.

Entende-se aqui que esta conduta seja, ao menos em parte, tributária da Criminologia midiática a que se refere Eugênio Raul Zaffaroni, em sua célebre obra "A questão criminal" (Zaffaroni, 2013).

\section{CONSIDERAÇÕES FINAIS}

O acompanhamento e a observação direta da estrutura e do funcionamento das audiências de custódia no Rio de Janeiro revelaram mazelas que só poderão ser superadas se bem compreendidas pelo próprio Tribunal de Justiça.

A estrutura com poucos servidores, a existência de dois sistemas de tecnologia diversos, o DCP para o Rio de Janeiro, e o SISTAC para o CNJ, que não dialogam, tornam o funcionamento das audiências e, sobretudo, os registros estatísticos não fidedignos.

Os bons resultados apresentados pela equipe multidisciplinar não têm qualquer metodologia que se possa confiar, na medida em que afirmam que menos de $1 \%$ dos presos que foram encaminhados à equipe multidisciplinar reincidem, mas quando se observam as audiências, verifica-se que os casos de reincidência dificilmente são encaminhados à equipe multidisciplinar.

A análise de conteúdo das atas de audiências desvelou um formato e um discurso padronizado, que pouco toma em consideração o caso concreto e termina por criar terminologias ao arrepio da lei ou de muito ultrapassadas cientificamente. É o caso da consideração a respeito da "periculosidade" a partir do tipo penal pelo qual o custodiado foi preso ou da "reincidência" tendo em conta à presença em audiências de custódia, ao invés do conceito legal.

São necessárias mais profundas análises que, a partir dos dados colhidos serão feitas em futuro trabalho, mas já é possível identificar os diversos problemas apontados a serem solucionados diante das observações feitas.

\section{REFERÊNCIAS}

ALVES-MAZZOTTI, Alda Judith; GEWANDSZNAJDER, Fernando. O método nas ciências naturais e sociais: pesquisa quantitativa e qualitativa. São Paulo: Pioneira, 2000.

BARDIN, Laurence. Análise de conteúdo. Lisboa: Edições 70, 2011. 
BRASIL. Tribunal de Justiça do Estado do Rio de Janeiro. Resolução TJ-RJ n29, de 26 de agosto de 2015. Disciplina a Audiência de Custódia no âmbito do TJ-RJ. Rio de Janeiro, 2015. Disponível em http://www.cnj.jus.br/. Acesso em 23 de fevereiro de 2017.

CHOUKR, Fauzi Hassan. Audiência de custódia: resultados preliminares e percepções teóricopráticas. Em: ANDRADE, Mauro Fonseca; ALFLEN, Pablo Rodrigo (org.). Audiência de custódia: da boa intenção à boa técnica. Porto Alegre: FMP, 2016, p. 105-126.

COUTINHO, Jacinto Nelson de Miranda. O papel do novo juiz no processo penal. Em: Crítica à Teoria Geral do Direito Processual Penal. Rio de Janeiro: Renovar, 2001, p. 3-55.

EILBAUM, Lucía. "Só por formalidade: a interação entre os saberes antropológico, jurídico e judicial em um" Juicio Penal. Horizontes Antropológicos, v. 18, n. 38, p. 313-339, 2012.

GIL, Antonio Carlos. Métodos e técnicas de pesquisa social. São Paulo: Atlas, 2008.

GOLDEMBERG, Miriam. A arte de pesquisar: como fazer pesquisa qualitativa em ciências sociais. 5. ed. Rio de Janeiro: Record, 2004.

KANT DE LIMA, Roberto; LUPPETI BAPTISTA, Bárbara Gomes. Como a Antropologia pode contribuir para a pesquisa jurídica. Um desafio metodológico. Anuário Antropológico [Online], 2014. Disponível em http://aa. revues. org/618. Acesso em 23 de março de 2017.

KANT DE LIMA, Roberto. Por uma antropologia do Direito, no Brasil. Em: FALCÃO, Joaquim de Arruda (org.). Pesquisa Científica e Direito. Recife: Massangana, 1983. p. 89-116.

LIMA, Marcellus Polastri. A Audiência de Custódia e a infeliz Resolução TJ no 29/2015 do Rio de janeiro. Em: ANDRADE, Mauro Fonseca; ALFLEN, Pablo Rodrigo (org.). Audiência de custódia: da boa intenção à boa técnica. Porto Alegre: FMP, 2016, p. 127-144.

LUPETTI BAPTISTA, Barbara Gomes. A pesquisa empírica no Direito: obstáculos e contribuições. Em: EILBAUM, Lucia; DE KANT DE LIMA, Roberto; PIRES, Lenin. Conflitos, direitos e moralidades em perspectiva comparada. Rio de Janeiro: Garamond Universitária, 2010, p. 127-152.

MARQUES, Mateus. Sobre a implantação da Audiência de Custódia e a proteção de direitos fundamentais no âmbito do sistema multinível. Em: ANDRADE, Mauro Fonseca; ALFLEN, Pablo Rodrigo (org.). Audiência de custódia: da boa intenção à boa técnica. Porto Alegre: FMP, 2016, p. 9-22.

MINAYO, Maria Cecília de Souza. Pesquisa social: teoria, método e criatividade. Petrópolis: Vozes, 2011.

REIS, Mauricio Martins. A Audiência de Custódia como exemplo privilegiado da bipolaridade da justiça constitucional brasileira: entre a afirmação normativa e a denegação pragmática de direitos fundamentais. Em: ANDRADE, Mauro Fonseca; ALFLEN, Pablo Rodrigo (org.). Audiência de custódia: da boa intenção à boa técnica. Porto Alegre: FMP, 2016, p. 23-46.

TRIVIÑOS, Augusto Nibaldo Silva. Metodologia da pesquisa em ciências sociais. São Paulo: Atlas, 1990. 
WHYTE, William Foote Ed. Participatory action research. New York: Sage Publications, Inc, 1991. Sociedade de Esquina:[Street Corner Society] A estrutura social de uma área urbana pobre e degradada. Rio de janeiro: Zahar, 2005.

Street corner society: the social structure of an Italian slum. Chicago: University of Chicago Press, 1955.

ZAFFARONI, Eugenio Raul. A questão criminal. Rio de Janeiro: Revan, 2013.

Trabalho enviado em 02 de setembro de 2017.

Aceito em 19 de outubro de 2017. 